\title{
LLANURAS INTERIORES DE JUAN ALCAIDE
}

JOSÉ MARÍA BALCELLS1

Universidad de León

\section{Resumen}

Este artículo analiza el libro de poemas de Juan Alcaide titulado Íntimo trébol, que fue reconstruido y publicado póstumamente, en 2001. El análisis se realiza exponiendo y valorando las características temáticas y formales de cada una de las tres secciones de que consta la obra.

Palabras clave: Literatura española. Siglo XX. Poesía. Juan Alcaide.

\section{Abstract}

This article analyzes the book of poems by Juan Alcaide which is entitled Íntimo trébol, published in 2007. This analysis consists of exposing and considering the thematic and technical features of the three sections of the work.

Key words: Spanish Literature. 20th Century. Poetry. Juan Alcaide

\section{Noticia de Íntimo trébol}

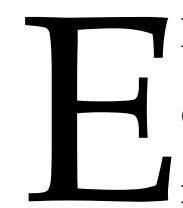

1 libro de Juan Alcaide Íntimo trébol no tuvo editor en vida del poeta, quien debió sentirlo mucho, porque había manifestado en repetidas ocasiones su intención de publicarlo² ${ }^{2}$ Sin embargo, el tiempo iba a ocuparse doblemente de compensar aquella voluntad no satisfecha, al haber coincidido que en torno a este conjunto girasen los dos homenajes que, en los albores del siglo XXI, se han hecho a

\footnotetext{
${ }^{1}$ Profesor de la Universidad de León. Correo-e: jmbald@unileon.es. Recibido: 07-11-2008.

$2 \mathrm{El}$ hecho de que Íntimo trébol pueda considerarse un libro no obsta para que su autor hubiese concebido, con anterioridad, al menos dos de sus secciones como conjuntos independientes, aunque en fase de desarrollo. Como obras en preparación son tenidas y valoradas, por ejemplo, Otra vez la campana y Pasión y soledad de Miguel Alvargonzález en la monografía de (Llamazares González, 2003: 234 y ss.)
} 
la memoria y a la obra del valdepeñero con motivo de sus dos primeros y emblemáticos aniversarios póstumos, respectivamente los del medio siglo de su muerte, y del centenario primero de su nacimiento. Y es que, en efecto, Íntimo trébol se editó inicialmente en Valdepeñas, en 2001, terminándose de imprimir el 12 de julio de ese año, cuando se cumplía con precisión matemática medio siglo del fallecimiento del escritor, acaecida aquel día de aquel mes, aunque de 1951, poco antes de sus cuarenta y cuatro de edad. Julián Creis Córdoba fue quien llevó a cabo esa edición, en coautoría con Matías Barchino, la cual incluye muy útiles y variadas anotaciones, y además reproduce, en regalo inapreciable para los lectores y estudiosos del poeta, los cuadernos y hojas manuscritas de la obra ${ }^{3}$.

Por mi parte, también he hecho objeto de mi atención este libro tras cumplirse, el 21 de septiembre de 2007, el primer centenario del nacimiento de Alcaide en Valdepeñas. De modo y manera que tanto editando como estudiando Íntimo trébol, acaso podamos arriesgarnos a decir que puede haberse hecho realidad algún más que ferviente deseo último de quien creó un conjunto tan memorable como Poemas de la cardencha en flor, de cuya aparición se cumplieron en 2007 sesenta años, pues se editó en $1947^{4}$.

Íntimo trébol consta de las composiciones procedentes de dos manuscritos, y de varias hojas sueltas, asimismo escritas a mano, en todos los casos precediéndolas un breve prólogo en prosa. El cuaderno inicial lleva por título Otra vez la campana, y comprende dos secciones, la primera de nueve textos, y la segunda, bajo el lema "Cuatro postales. Kodak del corazón hacia Galicia", de cuatro, y además una composición final, titulada "Envío". Por tanto, son catorce los poemas de la parte que encabeza el libro, cuyo centro lo ocupan las canciones agrupadas en las hojas que contienen Crucifixión ardiente de Sevilla, y que suman once. El tríptico se completa con los dos poemas que integran el cuaderno Pasión y soledad de Miguel Alvargonzález, es decir "La primer lágrima de Adán” y “Clima de infancia”, éste desarrollado en cinco

\footnotetext{
${ }^{3}$ (Alcaide Sánchez, 2001). El libro consta de 80 pp. más facsímiles de los manuscritos originales.

${ }^{4}$ El libro fue publicado en Barcelona, por Ed. Jabalón.
} 
sonetos. De cuanto antecede se sigue que en Íntimo trébol se reúnen veintisiete composiciones líricas, subdividiéndose la última, como se ha dicho, en cinco fragmentos, fragmentos que, si fuese admisible contarlos como poemas separados, propiciarían que la obra alcanzase, en total, la cifra redonda de treintaiún textos.

El período cronológico abarcado por esas composiciones no es inferior a una docena de años, los que median entre el poema, de la gavilla Otra vez la campana, "Calma de invierno", que se fechó en 1932, y los dos que constituyen Pasión y soledad de Miguel Alvargonzález, sección elaborada probablemente en el otoño de 1942, pues uno de sus textos, "La primer lágrima de Adán”, se dató en octubre de aquel año, y el preliminar a ambos dos meses después, en concreto el día 30 de diciembre, cuando estaban próximos a cumplirse los cuatro años de la muerte del autor de Campos de Castilla.

A tenor de los años entre los que se enmarca la confección de Íntimo trébol, cabe deducir que los textos de la obra pudieron escribirse en escenarios diversos, desde el de Galicia, que consta de modo expreso bajo el título de uno de los poemas ("Calma de invierno") de Otra vez la campana, hasta el de Andalucía, pues la serie Crucifixión ardiente de Sevilla pudo gestarse, entera o parcialmente, en la capital andaluza. Valdepeñas debió ser uno de los lugares de creación seguros, pero acaso también la localidad ciudarrealeña de Puerto Lápice, donde Alcaide enseñó en dos etapas de su vida, y donde por lógica se encontraría en octubre de 1942 cuando dató “La primer lágrima de Adán”. Después, ya en el período navideño, y en su ciudad natal, iba a firmar el prefacio de Pasión y soledad de Miguel Alvargonzález.

Uno de los principales méritos de la edición de Julián Creis Córdoba y Matías Barchino reside en haber reconstruido Íntimo trébol como libro, pues la mayor parte de los materiales de la obra ya habían sido dados a conocer previamente, bien en publicaciones periódicas, bien en antologías póstumas, como señalaremos a continuación basándonos en los datos que, en el transcurso de su labor, anotaban los editores en el apartado "Notas al texto". 
En las páginas que siguen se podrá comprobar que, pese a sus tres secciones, Íntimo trébol comprende elementos que le confieren un alto grado de cohesión, siendo uno de los más perceptibles la referencia a la infancia que se plasma a lo largo del conjunto. Otro factor lo determina un lirismo impregnado de religiosidad que se deja sentir en las dos primeras secciones, y que asoma en la última merced a "La primer lágrima de Adán". La métrica, finalmente, en virtud de las pautas semejantes que se practican en cada una de las partes, otorga al libro un notable ligamen formal y rítmico.

\section{Cronologías textuales}

Espigando en las informaciones consignadas en la edición de Íntimo trébol, sabemos que el poema "La Coruña", de "Cuatro postales", había aparecido en El Eco de Valdepeñas el 23 de diciembre de 1935, y sabemos igualmente que las composiciones del mismo grupo, "Orense" y "Pontevedra", se imprimieron en la entrega XXVI de la revista Garcilaso, en 1945, junto al soneto "Santiago de Compostela5". Asimismo sabemos que un par de textos de Crucifixión ardiente de Sevilla ("Dos de la noche” y “¡...Eso!”) salieron en la edición XXX de Albores, de Tomelloso, en abril de 1940, y que dos más de la serie los había publicado Alcaide en otros lugares: "La examinada" se imprimió en el folleto de Semana Santa del Campo de Criptana correspondiente a 1949, y en aquella misma primavera, en el número 12 de la revista Balbuena, salió "Bello morir".

Por tanto, fueron tan solo siete las creaciones de Íntimo trébol que Alcaide publicó en vida, o sea poco más de la cuarta parte del libro. Al respecto, remarcamos que, excepto el poema dedicado a "Lugo", vio publicados los otros tres de "Cuatro postales". Del cuaderno Pasión y soledad de Miguel Alvargonzález no iba a adelantar, en cambio, texto alguno, de modo que fue esta la única sección de la obra que, tras su

\footnotetext{
${ }^{5}$ El soneto a "Santiago de Compostela" no pasaría a formar parte de las "Cuatro postales", dedicadas en exclusiva a las respectivas capitales gallegas de provincia.
} 
fallecimiento, quedó completamente inédita, aunque no permanecería así por mucho tiempo.

Y es que "La primer lágrima de Adán", que va al frente de Pasión y soledad de Miguel Alvargonzález, figura en la Antología poética del autor que se publicó en Ciudad Real en 1954. En esta recopilación, prologada por Antonio Merlo Calero, se incluyeron también cuatro textos de Otra vez la campana, tres de ellos no publicados ("Agua", "Afilador" y 'Envío"). De cuanto antecede se sigue que, a los tres años de la muerte de Alcaide, únicamente se conocían catorce textos de Íntimo trébol, es decir casi la mitad de su índice completo. Más de cuatro lustros se demoraría luego la publicación de otras composiciones pertenecientes a la obra, en concreto veintidós años, los que median entre la antedicha selección de versos de 1954 y la que, con el mismo título de Antología poética, se publicó en Madrid, en 1976, editada por Doncel y con prólogo de Florencio Martínez Ruiz.

La recopilación de 1976 se editaba al cumplirse el cuarto de siglo de la muerte de Alcaide. En sus páginas se recogieron distintos inéditos de Otra vez la campana, los titulados "Otra vez la campana”, "Éxtasis", “Ángelus”, "Ser como tú...., "Calma de invierno", "La araña amiga” y “Ternero", además de completarse, con la edición del soneto "Lugo", el grupo de "Cuatro postales". Y excusado parece añadir que Martínez Ruiz no dejó de incorporar los otros textos de la misma sección que ya se conocían, de modo que, para ser publicada en su integridad, a Otra vez la campana solo le faltaba la impresión de su prólogo, escrito inédito rescatado para Íntimo trébol.

Al conocimiento de Crucifixión ardiente de Sevilla aportó la Antología poética de 1976 los siete textos que siguen: “Alba de lluvia”, "Íntegro amor”, “El domador de su llama", "Sangre de cirios", "La petición del nazareno borracho", "Voy" y "La noche aquella". A ellos adjuntaría los poemas del grupo que se habían publicado antes. Y por lo que hace a la parte tercera de Íntimo trébol, a la selección de Martínez Ruiz se le debe el hacer público el poema "Clima de infancia", acompañado de "La primer lágrima de Adán", con lo que quedaba completo el tríptico en lo que a las composiciones líricas se refiere. $\mathrm{Y}$ aquí es de justicia apostillar, a tenor de los 
materiales que conforman esta antología, que contiene casi todo Íntimo trébol, lo cual supone un mérito indudable, y el antecedente de la edición de la obra, en 2001.

Las gavillas líricas Otra vez la campana, Crucifixión ardiente de Sevilla y Pasión y soledad de Miguel Alvargonzález han sido unidas bajo el título compartido de Íntimo trébol por dos razones: de un lado porque con él se conjuntan en una misma obra tres grupos de poemas, a semejanza de cómo las hojas de los tréboles reúnen sus peciolos de tres en tres; y de otro porque el contenido de los textos del libro remite a ámbitos muy personales y profundos de Alcaide, aunque los surcos hollados en esos ámbitos no los hendiesen idénticas instancias sentimentales, sino bien distintas.

Las más hondas eran las familiares que, por vía materna, le ligaban a Sevilla, y que motivaron sus estancias en la capital sevillana, y singularmente la que transcurrió durante la Semana Santa de 1940, estadía en la que se originaron los textos de Crucifixión ardiente de Sevilla. Profunda fue también la huella que dejarían en el autor sus más de tres años de permanencia en Galicia ejerciendo como Maestro entre el 21 de junio de 1931 y el 14 de septiembre de 1934. Las impresiones vividas en ese tiempo están en el origen de los poemas de Otra vez la campana. Muy adentro, por último, le llegó al poeta el ejemplo humano y la palabra creadora de Antonio Machado, en cuya obra, pensamiento y persona se inspiraron los textos de Pasión y soledad de Miguel Alvargonzález.

Los tres grupos de poemas de Íntimo trébol no se secuenciaron atendiendo al grado de intimidad temática y emocional de los mismos, sino en atención a su cronología respectiva, y así principian el libro las composiciones de Otra vez la campana, que son las primeras en el tiempo, lo que no impide que su dedicatoria sea posterior, concretamente de 1942, pues en ella se alude al coetáneo cuarto centenario de San Juan de la Cruz, que había nacido en el abulense pueblo de Fontiveros en 1542. Crucifixión ardiente de Sevilla se sitúa en el epicentro de la obra, por haberse elaborado a partir de 1940, y culminándola va Pasión y soledad de Miguel Alvargonzález, cuyos textos habían sido escritos, según se adelantó más arriba, en el otoño de 1942. 


\section{Otra vez la campana}

Otra vez la campana lleva una dedicatoria que dice así: "A mis discípulos de Galicia. En este cuarto centenario de San Juan de la Cruz". Precede a los poemas del grupo un preliminar en prosa en el que Alcaide daba testimonio de su deuda con Galicia, de su agradecimiento a los lares galaicos que lo habían acogido, y en medio de cuya naturaleza se sintió renacer espiritualmente. Hacia ellos dice sentir un amor que crece con el tiempo, un apego y una querencia como la que sentiría un hijo por su madre, un manchego por su tierra madre gallega. Atestiguaba también el poeta en ese prefacio que sus sentimientos filiales a Galicia los había hecho revivir, en su interior, una circunstancia episódica, el escuchar de nuevo el tañer de una campana, el sonido característico que suele originarse en las torres de las iglesias. Siendo así, la serie de canciones recogidas en Otra vez la campana serían fruto de una nostalgia de Galicia en ligazón con el renacimiento de su religiosidad más sentida.

Y será esa reviviscencia del sentir religioso lo que se suplica en el texto inicial de esta gavilla lírica, nada casualmente emplazado al comienzo de la misma, porque en él se cifra su clave más honda. En coincidencia con el título de este cuaderno primero, "Otra vez la campana" es el verso con que comienza el poema, el cual culmina, como decíamos, con la desinteresadísima demanda de repristinación, en el espíritu, de la vivencia cristiana:

$$
\begin{aligned}
& \text {-Aunque sea, Señor, como castigo, } \\
& \text { siembra en mi voluntad matas de espliego. } \\
& \text { ¡Para aromar su brasa a mi enemigo }{ }^{6 !}
\end{aligned}
$$

La petición que acabamos de leer se efectúa utilizando léxico del ámbito de la naturaleza, en un empleo en coherencia con esa voluntad que se quiere identificada con el aroma puro de las matas de espliego. Esta pretensión es acorde con una poética que interioriza el mundo natural aspirando a una unión armónica con la

\footnotetext{
6 Íntimo trébol, 27.
} 
tierra que se fue ostensibilizando crecientemente en su obra poética7, y que también se halla en la estrofa con que principia "Éxtasis", segundo de los poemas de Otra vez la campana, en cuyo tercer verso se dice: "La tarde, esclareciéndome de arcilla". Pero no es esa la vertiente que domina en la composición, sino el testimonio del despertar, a través del paisaje del noroeste céltico, del sentimiento religioso inculcado en la más temprana niñez, de ahí que sea invocada Rosalía de Castro, al fin del texto, para que ella, asumiendo su faceta materna, acune aquel corazón infantil:

$$
\begin{aligned}
& \text { Dulce Belén de tiempo joven. } \\
& \text { Domingo celta, gaita y sueño... } \\
& \text { Como una piedra afiladora, } \\
& \text { mi corazón te lo devuelvo. } \\
& \text { ¡Brízalo tú, mi Rosalía, } \\
& \text { sobre la rueda de los vientos! }
\end{aligned}
$$

Bajo el título del tercero de los poemas puso Alcaide una cita de Francis Jammes, cita que dice así: "Voy por el camino como va el asno con su carga...". A continuación, sin embargo, quiso mejorar su contenido cambiando la comparación, y por eso escribe: “Mejor aún -sigo yo- como va el buey con su silencio...Suena el Ángelus". De este modo queda más justificado el pretexto de este poema lírico que tituló “Angelus", y que se inspira en el misterio de la Encarnación para transmitir a los lectores imágenes de sencillez y calma aldeanas ${ }^{9}$, de pureza y de bondad espirituales. Esta poetización no queda distante, tampoco, del universo del citado escritor francés, cuya lírica melancólica y simbolista es bien perceptible en sus obras, entre ellas De L'angélus de l'aube à l'angélus du joie (1898). En la estrofa con la que se

\footnotetext{
7 Un estudio sobre esta veta crucial en su obra es el realizado por P. A. González Moreno con el título de "Juan Alcaide: el paisaje interior" (1988: 103-107). Del mismo autor, véase también "La gracia de la espiga: Penúltima reivindicación de Juan Alcaide" (2004: 56 y ss.)

8 Íntimo trébol, 28.

${ }^{9}$ En Colmena y pozo (1930) incluyó Alcaide un poema, "La campana del 'Ángelus", que presenta varias convergencias con éste de Otra vez la campana.
} 
abre "Éxtasis" reaparece el motivo de la campana, esta vez anunciando la redentora concepción de María:

\author{
El sol quita su hogaza \\ del linar florecido. \\ La campana echa al viento su enagua de rapaza, \\ y en el badajo le palpita un nido ${ }^{10}$.
}

El siguiente poema, "Ser como tú...", constituye un ejemplo muy ilustrativo de esa ansia de identificarse con elementos del entorno natural que tanto apremió a Juan Alcaide, y que tantas veces se plasmaría en imágenes expresando la equivalencia entre su ser y el de la naturaleza botánica. En dicha composición, el hablante manifiesta su anhelo de parecerse al castaño, en virtud de unas características del fruto de ese árbol que quisiera para sí, las de escudarse mediante una protectora y punzante coraza exterior. Con estos versos lo dice en la tercera y última de las estrofas:

$$
\begin{aligned}
& \text { Ser como tú, castaño, este árbol mío } \\
& \text { que se me va del suelo y se me astilla. } \\
& \text { Llevar envuelta el ascua en hierro frío. } \\
& \text { La carne, de madera; y dentro, un río } \\
& \text { de sangre verde, cobre y amarilla11. }
\end{aligned}
$$

Alcaide sustituye la comparanza de la naturaleza vegetal por la líquida en el poema "Agua", vertebrado por las metáforas de Dios como Molinero, de la vida como molino, y del agua como rezo necesario para su funcionamiento. En su virtud, el hablante se identifica con la muela de agua que, al igual que el regato, está rezando sin saberlo, y de continuo. Convencido de ello, insta a su alma a seguir rezando,

\footnotetext{
10 Íntimo trébol, 29.

11 Íntimo trébol, 30.
} 
porque nada le pasa desapercibido a Dios: “Sigue rezando, vida mía.../ ¡Nunca se duerme el Molinero!"12.

La sexta de las composiciones de la serie, "Calma de invierno", es la única que aparece fechada, pues bajo su título consta: “(Galicia-1932)”. La estampa galaica que se plasma en el poema es invernal y aldeana, amén de presidida por una mansedumbre que se relaciona, como ocurría en "Ángelus”, con María Virgen, toda vez que en dos oportunidades se refiere el poeta al rezo del rosario, imaginado como bonancible "ritmo de cuna" para las odiseicas vicisitudes del alma humana.

Si en "Agua" vimos cómo el regato rezaba, en "La araña amiga" un viejo telar contará una historia amorosa cuyo desenlace no se declara, pero sin duda es triste, según apuntan dos indicios: la lágrima que asoma a los ojos del hablante en su evocación de la escena, y el llanto del propio telar, que llora por aquella ilusión de boda que un día tuvo la moza, y que no culminó, condenando a la joven al monótono y cotidiano sonido de la máquina para tejer, convertida en la inseparable compañía, idea recogida en el título antedicho, de "La araña amiga".

La virtud del silencio, como vía para profundizar en el alma, es encarecida en la composición "Afilador", que el hablante inicia comparando su lengua con una navaja, una navaja triste y mullida, adjetivo éste que simboliza la soberbia humana. Y ese pecado hay que combatirlo, hay que limarlo, en una tarea que recuerda la que hace el afilador cuando pasa la navaja por su muela para pulirla. Imagina el poeta, al término del texto, que obtendrá un contento interior enorme tras un pulido que debe ser muy intenso, y por eso exclama:

\footnotetext{
¡Oh afilador, afilador!...

¡Un cuajarón de lacre divino en mi garganta!

¡Cuánto voy a charlar con el silencio!

¡Qué bien voy a palparme toda el alma ${ }^{13}$ !
}

\footnotetext{
12 Íntimo trébol, 31.

13 Íntimo trébol, 36.
} 
Entre el poema “Afilador" y el que le sigue, “Ternero", percibimos el ligamen de que en los dos se alaba el silencio, y en los dos se reprenden vicios. Antes se vituperaba la soberbia. Ahora lo será la vida sin afabilidad, la ambición. Comparada su alma con la de un ternerillo, le recomienda que se sosiegue, que no corra enloquecidas aventuras y que, sobre todo, acepte los sacrificios que Dios disponga:

$$
\begin{aligned}
& \text { Procura ser como Dios quiere: } \\
& \text { lengua de amor santificado } \\
& \text { sobre el cuchillo que te hiere }{ }^{14} \ldots
\end{aligned}
$$

\section{Cuatro postales}

El grupo "Cuatro postales" lo vertebran otros tantos sonetos pretextados, principalmente, por las cuatro capitales gallegas de provincia. La colocación de los poemas en ese manojo textual se ajusta a la secuencia de su ordinaria enumeración, determinada por el mapa de Galicia visto de Norte a Sur, y así las composiciones se inspiran, sucesivamente, en La Coruña, Lugo, Orense y Pontevedra. En el subtítulo puesto debajo de "Cuatro postales" se menciona una nombradísima marca comercial de carretes para cámaras de fotografiar, indicándose por vía indirecta que Alcaide pretendió la realización, en verso, de una suerte de retratos fotográficos que, no por serlo, fuesen epidérmicos, sino penetrantes y reveladores de los perfiles captados en cada ciudad y en su caso provincia, los perfiles que en cada una le llegaron más adentro, recreándolos “desde el corazón”.

No fue precisamente el de la alegría el sentimiento primordial evocado por el poeta en su remembranza de La Coruña, entrevista en su campiña, y leída sobre todo desde su orilla costera y portuaria. La estrofa de apertura diríase que responde a una entera panorámica coruñesa, metaforizada como "cangrejo de cristal". La segunda apuntaría al interior de la provincia, a su huerto dulce no carente de meigas, henchido de penas rosalianas, refiriéndose también a los encantadores extremos de

\footnotetext{
14 Íntimo trébol, 37.
} 
sus ríos. Tanto la llamada "costa da morte" como las "rías altas" tal vez estén aludidas en este cuarteto. La emigración gallega es tema del primero de los tercetos, mientras el que cierra el texto se centra en el monumento romano de la "Torre de Hércules", faro orientador para los navegantes imaginado como "dedo de piedra" e "indice divino".

Con ser la lucense la provincia más extensa de Galicia, el soneto "Lugo" se ciñe a la capital, una ciudad con muchos atractivos, entre ellos su maravillosa muralla romana, pero que al poeta no le fue posible visitar, limitándose a verla de lejos y tangencialmente, desde la estación ferroviaria. En una primavera gélida pudo haber tenido lugar el fugaz roce con esa urbe a orillas del Miño que Alcaide atisbó entre tamices nostálgicos y melancólicos. Como en la composición a La Coruña, tampoco la alegría y el gozo caracterizan la perspectiva que aquí plasma el escritor de Valdepeñas, pues al referido gran río lo captó “desangrándose en sangrías”. En el terceto final, y pese a no haber andado por sus calles, confiesa el estremecimiento que sintió con aquel mero y efímero contacto con la villa, hasta el punto de afirmar en el endecasílabo catorce, y no sin connotaciones léxico-religiosas: "sentí toda mi sangre traspasada".

A diferencia del poema "Lugo", dedicado a una ciudad prácticamente desconocida para él, en el soneto "Orense" dejó testimonio de su sintonía con la urbe y provincia de ese nombre, las cuales tampoco escaparon, sin embargo, a un enfoque un tanto desapacible, aunque fidedigno. Alcaide calificó a Orense como "provincia provinciana", pudiendo alegar en pro de lo veraz de esa adjetivación sus años de permanencia en esa comarca galaica de interior, de la que cita de modo expreso sus características burgas, o manantiales de agua caliente. La melancolía y la tristeza del emigrante, señaladamente la del habanero, son enunciadas en las dos estrofas finales, deteniéndose los cuartetos en la capital orensana, cuyo puente romano bajo el Miño se evoca nada más iniciarse el poema, y a cuyo Cristo tras el Descendimiento, que se 
venera en la Catedral de la ciudad, alude al referirse a "...ese Cristo tremendo y febriscente/ con un pelo de espanto en piel de greda"15.

El prisma con el que interpretaría Pontevedra, en el soneto de este título, no está presidido por tonalidades grisáceas, sino por la luminosidad versus el dinamismo. El poeta concibió, en efecto, la idiosincrasia de la provincia a través de la tensa dialéctica mantenida entre dos ciudades contrapuestas, la capital y su gran puerto pesquero, el de Vigo. A la una la distinguiría la luz y la oración. Al otro, las ambiciones y la intriga. Así se lo cantaba el escritor a la urbe pontevedresa, con aires de cantiga medieval galaica, como si Vigo fuese, a la vez, su amor y su tormento, aquella pena que produce en la amada quien se ausenta por las procelosas aguas atlánticas.

Sigue a "Cuatro postales" el poema "Envío", de título idéntico al que cerraba la primera de las entregas poéticas alcaldianas, A Madre Cándida (1929), e idéntico también al que lleva la composición de apertura de Mimbres de pena (1937). Aquí, en Otra vez la campana, "Envío" traduce una evocación emotiva de los alumnos a quienes el escritor enseñó durante su período orensano de docencia. Al recordarlos, augura que, como tantos y tantos gallegos, emigrarán de su solar nativo hacia otros horizontes, desde los más lejanos de América hasta los más próximos del interior peninsular, así Castilla y, más al Sur, las tierras del vino, en alusión implícita a Valdepeñas y acaso también a Andalucía. En sus caminos, llevarán siempre determinados elementos que conforman su idiosincrasia, como las cantigas de Curros Enríquez, su perfil céltico, sus saudades...Irán por doquier, y el poeta va a sentirse orgulloso de sus pasos, sabiéndolos de algún modo suyos. En la última estrofa les participa sus deseos de que la Virgen y Santiago velen por ellos.

El cuaderno Otra vez la campana principia, desde su vertiente métrica, combinando un serventesio con un quinteto, y finaliza con un "Envío" en versos blancos, precedido de los sonetos que integran "Cuatro postales". Varios poemas se encauzan en serventesios (“Éxtasis”, “Ángelus”, “Calma de invierno”), rematados a

\footnotetext{
${ }^{15}$ Íntimo trébol, 43.
} 
veces con un quinteto ("Ser como tú...", "La araña amiga", "Ternero") o con otras opciones rítmicas ("Agua”), lo que acredita que el serventesio fue una de las estrofas más del gusto de Alcaide ${ }^{16}$. Composición de rima arromanzada es "Afilador".

\section{Crucifixión ardiente de Sevilla}

Como ya se adelantó, Juan Alcaide estuvo en Sevilla en 1940, con ocasión de la Semana Santa de ese año, y en esa estadía fueron brotando los poemas de Crucifixión ardiente de Sevilla, en una realización creativa que trae a la memoria el precedente de la serie poemática inspirada en la visita a esa ciudad en junio de 1930, y de la que nacieron la docena de poemas que, bajo el título "Horas azules", iban a integrarse en Colmena y pozo. Entonces fueron lugares muy característicos (Glorieta de Bécquer, Barrio de Santa Cruz, Giralda, Jardines de Murillo, Torre del Oro, etc.) uno de los hilos conductores de la serie, pero en la estancia llevada a cabo una vez finalizada la guerra civil, fue el principal la desolación religiosa sentida al compás de las manifestaciones populares en las jornadas procesionales.

El poeta pudo a la sazón ver salir las imágenes pías de sus respectivas iglesias, y también pudo contemplarlas y meditar sobre ellas en diversos puntos de sus recorridos callejeros, experimentando sentimientos muy personales en su interiorización de lo que esas tallas devotas representan. Al respecto, bajo el título de algunas de las composiciones está indicado el avatar circunstancial que las pretextó. A propósito de "Alba de lluvia", por ejemplo, se puntualiza: "Siguiendo el 'Cachorro', que no pudo volver", es decir que no pudo retornar a Triana, de donde partió, a causa de la lluvia. Respecto a "Dos de la noche", se concreta el punto en el que se vio la imagen: la Plaza de San Lorenzo, en la que se encuentra la Basílica de

\footnotetext{
16 Solía emplearlas en secuencias de indeterminado número de ellas, y de no menos diferenciado cómputo silábico, pues ya en su primer libro, Colmena y pozo, se registran serventesios eneasílabos, endecasilábicos, con versos de doce, con alejandrinos y con líneas de dieciséis sílabas, una notable variedad de cómputos reveladores de su apego a la fórmula del también conocido como cuarteto de rimas cruzadas, el cual está presente en la mayoría de sus libros, así en Llanura, Ganando el pan, Poemas de la cardencha en flor, Jaraíz (1950) y La octava palabra (1953).
} 
Nuestro Padre Jesús del Gran Poder. Y a vueltas de “El domador de su llama" y de "La examinada", en ambas aclaraciones consta que las imaginerías de 'El Señor de la Pasión' y de 'La Macarena' iniciaban su andadura urbana. En cambio, en "Bello morir" se especifica que el 'Cristo de la Buena Muerte' fue visto mientras pasaba.

Había en el poeta de Valdepeñas, muy a mayores, una motivación añadida para integrarse en el ambiente de religiosidad popular en torno a los pasos procesionales sevillanos, como señalábamos mucho más arriba: el enraizamiento en Sevilla derivado de su ascendencia materna, la cual le predisponía a sentir, con ocasión de la Semana Santa de la capital andaluza, un "trágico mareo a lo divino", según sus propias palabras. La citada frase la utilizó Alcaide en un breve prefacio a la serie de composiciones de las que vamos a ocuparnos, y a las que su autor, en ese mismo prologuillo, denominó "férvidos apuntes -versos al temple, encandilados, ebrios ${ }^{17 \prime \prime}$.

Advertía Creis Córdoba en sus "Palabras previas" a Íntimo trébol que la parte más imprecisa de las tres que comprende el libro era Crucifixión ardiente de Sevilla, alegando como prueba el hecho de que los poemas de esa serie se hallan en hojas sueltas, y por tanto no ordenados sucesivamente en un cuaderno. Y no le faltaba base en ese parecer, toda vez que, tocante a la estructura de la sección, algunas composiciones podrían intercambiar su lugar con otras sin que se resintiese el significado catárquico del conjunto.

También resulta cierto, de todos modos, que algún que otro poema pudo haberse dispuesto diferentemente, tal vez por su secuencia temporal, como por ejemplo el que abre la serie, inspirado por 'El Cachorro', y que sucede en el marco del Viernes Santo, mientras los que le siguen inmediatamente acontecen durante la llamada "madrugá" de ese día, es decir se refieren a las horas previas, y en cambio están situados después, no antes, como exigiría un riguroso orden cronológico. En cualquier caso, en vista de la imposibilidad de conocer a ciencia cierta el diseño que

\footnotetext{
17 Íntimo trébol, 49.
} 
habría decidido su autor, nada obsta para que comentemos los once textos del grupo siguiendo la colocación en la que fueron editados en la obra.

El primero de los poemas, "Alba de lluvia", parte de una anécdota no demasiado infrecuente en el Viernes Santo sevillano, la del aguacero que con alguna asiduidad desluce el recorrido penitencial. Esa perturbación meteorológica debió producirse aquel año de 1940, y el poeta da fe de ello, habiendo sido testigo de que la imagen barroca del 'Santísimo Cristo de la Expiación', también conocida como 'El Cachorro' porque su autor de la obra se inspiró en un gitano moribundo que tenía ese mote, no pudo regresar a su iglesia trianera, de donde había salido, como consecuencia de la pertinaz lluvia de madrugada. El agua caída, la impresionante escultura del crucificado de boca entreabierta, y Triana, son los tres protagonistas principales de una composición que culmina con el "milagro" de una talla moviendo los labios para exclamar: “¡Ay!, / ¡No me dejéis morir sin mi Triana18!”

El segundo de los textos se titula "Íntegro amor", y refleja la contemplación admirativa y devota expresada por el hablante al ver la imagen de 'Nuestra Señora de la Esperanza' en la sede donde se hallaba en 1940, la iglesia trianera de San Jacinto, en la que en ese tiempo permanecía hasta que, el Viernes Santo de 1962, fue trasladada otra vez a su primitiva ubicación, en la calle Pureza. Precedidos por un versículo del Cantar de los Cantares, los versos del soneto ensalzan la hermosura de María, así como su adecuadísima realización escultórica, finalizando el texto con el compadecimiento hacia su duelo por parte de quien, en su "morir descolorido", aspira a ganarse el amor mariano.

Muy emotivo es el soneto que sigue, bajo el título de "Dos de la noche". Merced al vocablo "Dos" pudo referirse Alcaide a sí mismo, y al 'Jesús del Gran Poder' que consta inspiró los endecasílabos de ese texto. En ellos se explicita cómo el Crucificado, al paso de su talla barroca, va despojando al hablante de su "carcoma" mientras le deja, al mismo tiempo, su luz.

\footnotetext{
18 Íntimo trébol, 51.
} 
El tercero de los sonetos lo pretexta la imponente imagen artística que talló Juan Martínez Montañés en 1615. En el poema, el hablante se constituye en espectador del comienzo del itinerario del paso recién salido de su templo, la iglesia parroquial de la plaza del Salvador. Alude Alcaide en sus versos a una vertiente del silencio de Dios que no suele ser ponderada, la de no hablar ni siquiera para quejarse, la de no romper su silencio por el desdén de matar el quejido. A la afección del desdén agrega luego la de la altivez, paradójicamente atestiguada en la aceptación de la cruz. Mientras la imagen de Cristo la estaba llevando a cuestas a lo largo de la carrera asignada por la ciudad, imagina el poeta que la propia Sevilla es la que hace las veces de Verónica en su rostro. El título elegido por Alcaide para el quinto de los poemas de la serie, "Bello morir", refleja con precisión lo que el artista Juan de Mesa intentó plasmar en la talla del Crucificado a la que puso fin en 1620: el instante exacto en el que Cristo expiró, leído como una muerte tan serena que, si uno se fija en su cara, semeja haberse dormido, tanta es la paz que de él dimana. A ella alude el poeta en la tercera de las estrofas, en la que también, en contrapunto, describe con una vívida imagen el fragor, aún actuante, de su herida más emblemática: “Tu rostro, en paz. / La rosa y el carbunco, / luchando en tu costado"19.

El paso del 'Cristo de la Buena Muerte' que inspiró la composición está encuadrado en medio de cuatro imponentes cirios de gran tamaño a los que Alcaide se refiere en sendas estrofas. En la segunda menciona las "Cuatro estacas de cera, fantasmales." Después, en la quinta se expresará más dramáticamente, diciendo: "Cuatro cirios tremendos, desangrados/ sobre un Guadalquivir de corazones". El texto se remata con el intento de desciframiento de un mensaje que acaso pudiera albergarse en la paradójica pasión armónica plasmada por el imaginero en la escultura de Cristo, cuyo pensamiento interpreta y traduce el escritor de Valdepeñas en los dos endecasílabos finales que encierran la invitación a asumir el padecer de la Cruz por parte de los sevillanos:

\footnotetext{
19 Íntimo trébol, 55.
} 
-¡Yo te daré mi muerte más amable, si bebes mi sudor, Sevilla mía!20

De una única estrofa se compone el sexto de los poemas de Crucifixión ardiente de Sevilla. Titulado "Sangre de cirios", se formula como pregunta explícita a la figura del San Juan de San Juan de la Palma. La efigie a la que se interpela forma conjunto con la de la Virgen, estando al lado izquierdo de María, en este camerín denominada 'Nuestra Señora de la Amargura'. En el texto se pondera la fiebre que se transluciría en las mejillas del santo, a quien se inquiere por su rumbo teniendo tan cercanos a sus sienes tantos cirios.

En marcado contraste con el contenido de las composiciones del grupo, la titulada "La petición del nazareno borracho" se inspira en un supuesto no infrecuente en el anecdotario folklórico que acompaña el cortejo penitencial de la ciudad: el de las copitas de más tomadas por algunos nazarenos participantes en la procesión. A veces, esas personas beben hasta emborracharse, dando las nota pintoresca, que es precisamente lo que Alcaide retrata en sus versos, haciendo gala del gracejo andaluz que, por ascendiente familiar, llevaba en sus venas. Dado su carácter excepcional, aunque no menos típico de la Semana Santa sevillana, será oportuno trasladar aquí el texto entero de este poema, en cuyo decurso último sube de punto el humorismo a vueltas de la sorna con la que un nazareno bebido le hace una petición muy irreverente al 'Cristo de los Gitanos' trianero:

De tantas "manzanillas"

ya, mi Señor, no puedo

llevar más aire azul a las costillas.

Y cual lirios de miedo,

de acera a acera, asombro en las aceras,

me perfuman las eses de mi ruedo

-toros de soledad-las dos ojeras,

\footnotetext{
20 Íntimo trébol, 56.
} 
que me las voy pisando en un enredo.

Señor de los Gitanos:

Tú que puedes hacerlo, por un día,

deja un poco tu Cruz, dame tus manos...

¡y ayúdame a llevar la carga mía ${ }^{21}$ !

La 'Macarena'22 tiene muy distinto protagonismo en el par de poemas que van a continuación, “i...Eso!" y "La examinada", porque en el primero sólo se le dedica una estrofa, mientras el segundo gira, en exclusiva, en torno a la Virgen. En “¡...Eso!”, efectivamente, lo crucial es el testimonio del hablante atestiguando haber revivido su fe cristiana gracias a la Semana Santa de Sevilla. Se halla meditando ese renacimiento interior cuando

\section{Viene la "Macarena" en su agobio} de trágicos piropos de colores...

(Todo el aire es amor, como de novio²3).

"La examinada" se dedica a "María de la Esperanza, la 'Macarena', saliendo de prestado de la Universidad", dedicatoria alusiva al comienzo de su recorrido desde el lugar provisional que ocupaba en 1940, la Capilla de la antigua Universidad, a la que se había trasladado a raíz de que, en 1936, se incendiase su templo de San Gil Abad, a cuya parroquia regresaría en 1942. En este poema tomó Alcaide como excusa la ubicación de la imagen en la capilla universitaria para deducir el argumento de haberse examinado en sus aulas, pero de la dura materia del duelo por el sacrificio de Cristo, en una dolorosísima prueba martirial en la que alcanza la más alta nota, como se acredita en las dos estrofas con que termina la composición:

\footnotetext{
21 Íntimo trébol, 58.

${ }^{22} \mathrm{La}$ 'Macarena' ya había inspirado un poema de Colmena y pozo, el doceavo de la serie "Horas azules".

23 Íntimo trébol, 59.
} 
Llorarás siempre ya. Como alfileres, te volverá a pinchar tu sal volcada. Cursas muerte divina y siempre mueres, martirizadamente examinada...

Reclama el corazón cuando suspira, veranos de un San Gil para tu pena. Sales. Se cuaja el tiempo. Se azafira. Y en un sobresaliente de luz buena, la faz de ayer se nos revive y mira ${ }^{24}$.

El penúltimo de los textos del grupo es “Ver...". En él se poetiza el conflicto entre las dos dimensiones antitéticas anidadas en el hablante, la decantación carnal y la espiritualidad del amor a Cristo. Comienza la andadura del poema con la ilustración de ambas facetas mediante imágenes ad hoc y, así, la vertiente pecadora será su "nazareno", su "gallo de Pedro", su "Judas". Pero el arrepentimiento reconduce ese lado culpable por el sendero de la aproximación al Crucificado, lo que asimismo se ejemplifica con expresiones como "doliente" y "llanto". Como la Semana Santa de Sevilla propició esta contrición, el Guadalquivir habría hecho las veces de personal Cedrón, aludiéndose al torrente junto al Huerto de los olivos en el que Jesús oró antes de su Pasión. Contextualizada esta penitencia en el Viernes Santo, culmina la composición con la súplica de que Dios le conceda recibir una herida corporal semejante a la que se infringió a Cristo en la Cruz:

-Dios padre, imaginero de los Cristos; ¡ábreme un San Lorenzo en mi costado 25 !

La serie se cierra con el poema "La noche aquella". Se dedica "Al discípulo amado", empleándose una expresión bíblica inconcreta, y aun enigmática, pues no

\footnotetext{
24 Íntimo trébol, 61.

25 Íntimo trébol, 63.
} 
existe acuerdo en precisar a quién hace referencia. Sin embargo, es muy compartida la hipótesis de que ese "discípulo amado" cuyo nombre no se especifica en el texto testamentario puede ser el apóstol Juan, al que tradicionalmente se había atribuido el Cuarto de los Evangelios. Alcaide debió estar entre quienes sustentaron esa convicción tan extendida, y por tanto no parece arriesgado concluir que el personaje de su composición sea Juan Evangelista.

A favor de tal creencia podría alegarse incluso un argumento endógeno a Crucifixión ardiente de Sevilla, el de que el poema presenta coincidencias con otro que se comentó con anterioridad, "Sangre de cirios", inspirado en un conjunto artístico en el que dicho apóstol está a la vera de la Virgen y es visto con "fuego en las mejillas". Bajo esta misma perspectiva imagina el poeta a ese discípulo tan especial en la composición que comentamos, y que comienza con las dos estrofas que siguen, y que constituyen la primera mitad de "La noche aquella":

Por tu mejilla se notaba: ardía.

Todo el amor se te subió en marea.

Sobre la vida encanijada y fea,

tu doble flor de pómulos se abría.

La Madre iba a tu lado. Y tras tu dedo.

Lo hincabas en la noche aterradora.

¡Cuánto ardor sobre el cálculo y el miedo!

¡Cuánta luna en tu sombra! (¡Cuánta aurora²6!)

En la que pudiera considerarse segunda parte del poema, se enfatiza la constante renovación del trato simbólico establecido entre Sevilla y el dolor del Santo frente a la nocturna entrega de Cristo que acabaría en su crucifixión. El poema finaliza manifestando el hablante su anhelo de andar, en espíritu, junto al apóstol, y asimismo el de identificarse con él en trance tan doloroso:

\footnotetext{
26 Íntimo trébol, 64.
} 
Hoy voy de condiscípulo contigo.

Quiero ser tú. Si en vuelo más te obligo,

¡dulce el dolor que se traduce en alas ${ }^{27}$ !

Las pautas métricas de Crucifixión ardiente de Sevilla guardan semejanza con las de Otra vez la campana, pues también en esta sección se valió el escritor de sonetos, coincidiendo en el mismo número de ellos, en los poemas “Íntegro amor”, “Dos de la noche", "El domador de su llama" y "Eso". En los restantes textos dominan los serventesios y en menor medida los cuartetos ("Sangre de cirios", "La noche aquella"), siendo la rima arromanzada la fórmula que se empleó en "Voy". Y excusado parece añadir, tratándose de Juan Alcaide, que en varias composiciones se incorporan mezclas y variaciones relativas a los versos y a las estrofas.

\section{Pasión y soledad de Miguel Alvargonzález}

Cierta aura religiosa impregna la dedicatoria pensada por Alcalde para Pasión y soledad de Miguel Alvargonzález, pues dice: "Al divino recuerdo del eterno Maestro", voz esta ultima en mayúscula. En cualquier caso, estas palabras no hacen sino subrayar la extraordinaria adoración sentida por el de Valdepeñas por Antonio Machado, quien se había expresado elogiosamente sobre Alcaide como poeta, en una carta que fue reproducida en el conjunto Llanura (1933). El influjo del lírico bético fue notabilísimo en su obra, en la que es aludido de vez en vez, y de quien en ocasiones cita pasajes, y en cuyo recuerdo y homenaje llegaría a componer, y a publicar, varios poemas, así los que tituló “Antonio Machado", de Colmena y pozo, "Nueva oración", de Poemas de la cardencha en flor y "Amor a Antonio Machado", de Jaraíz.

En Íntimo trébol, el reconocimiento a quien creó Campos de Castilla lo constituye su tercera parte, remarcándolo el prólogo redactado como presentación, en cuyo inicio se lamentaba Alcaide de haber tardado cuatro años, desde que con enorme dolor conoció la noticia de la muerte de Machado, en rendirle tributo humano y

\footnotetext{
27 Íntimo trébol, 64.
} 
literario. Transcurrido ese tiempo, lo hacía por fin merced a dos textos, "La primer lágrima de Adán”, y "Clima de infancia”, sobre el primero de los cuales realizó en dicho prefacio un muy interesante y esclarecedor comentario.

En él atestiguaba que siempre le angustió la pregunta sobre cuándo Adán había llorado por primera vez, proponiendo como respuesta que fue con ocasión del fratricidio acaecido en su familia. Acto seguido, cambia de escenario para pasar, del bíblico al del relato machadiano "La tierra de Alvargonzález", intersectando una historia con otra merced a la idea de que Miguel Alvargonzález, el indiano que regresó a sus lares cuando ya sus hermanos habían asesinado a su padre, se le figuraba “un poco Adán también”. Y Adán porque lloró a causa de otro crimen familiar, aunque de distinta índole. Según su parecer, el llanto del menor de los Alvargonzález podía referirse al padre o a los hermanos, y sin duda a sí mismo, en una lectura de señalado valor interpretativo: "He aquí también un importante símbolo de Machado ante España en plena lucha"28. Apurando esta posibilidad, identifica Alcaide en un mismo espíritu a Adán, a Miguel Alvargonzález y a Antonio Machado, por mor de que los tres deploraron un sangriento crimen familiar, el poeta de Sevilla durante sus días de exilio. En el párrafo último del prólogo, fiaba Alcaide en Dios tener fuerza bastante para retornar a un asunto tan terrible, pero abordándolo desde el teatro.

La composición “La primer lágrima de Adán” se va desarrollando a base de serventesios endecasilábicos. Su argumento, a través del tan machadiano universo de los sueños, hace interferir la escena del llanto primero de Adán con la del sueño en el que, miles de años después, el menor de los Alvargonzález no acierta a identificar si le están llamando por su nombre, o por el de Adán, idea que podría haberle sido sugerida a Alcaide por el recuerdo de un verso de Machado, el que da principio al poema LXIV de la serie "Galerías": "Desde el umbral de un sueño me llamaron", endecasílabo reproducido por el de Valdepeñas bajo el título de su composición, según la cual el fratricidio habría desencadenado las lágrimas de Adán, y el

\footnotetext{
28 Íntimo trébol, 68.
} 
parricidio las de Miguel, pero ambos supuestos serían dos caras de un mismo crimen sobre individuos estrechamente unidos por la misma sangre.

El ligamen realizado por Alcaide entre esos dos tipos de asesinatos familiares podría entenderse que se desprende de la narración de Machado, puesto que sentenció en una célebre cuarteta de su relato

$$
\begin{aligned}
& \text { Mucha sangre de Caín } \\
& \text { tiene la gente labriega, } \\
& \text { y en el hogar campesino } \\
& \text { armó la envidia pelea }{ }^{29} \text {. }
\end{aligned}
$$

Cabría derivarse del sentido de estos versos que el parricidio del padre no supone sino una forma de cainismo, y esta percepción machadiana habría inspirado el argumento que plasmó Alcaide en “La primer lágrima de Adán”, argumento que iba a enriquecer el poeta de Valdepeñas identificando a Miguel Alvargonzález con Machado, si es aceptable la hipótesis que pudiera deducirse de la penúltima estrofa del texto:

$$
\begin{aligned}
& \text { Miguel salió a la puerta. El sol ponía } \\
& \text { su franciscana miel sobre las cosas. } \\
& \text { Volviéronle a llamar. ¿Qué sueño había? } \\
& \text { Y halló un sur de Giraldas y de rosas }{ }^{30} \text {. }
\end{aligned}
$$

Una doble identificación estableció Alcaide en "La primer lágrima de Adán": la del primer hombre bíblico con Miguel Alvargonzález, y la de éste con Antonio Machado, en una tríada de identificaciones que no hace sino remarcar un posible ascendiente machadiano, pues resulta bien conocida la tendencia del poeta de Sevilla hacia el juego plural representativo (Echeverría ,1985: 118 y ss.)

\footnotetext{
${ }^{29}$ Machado $(2007,178)$.

30 Íntimo trébol, 71.
} 
A la segunda de las equivalencias mencionadas se circunscribe el poema "Clima de infancia" 31 , y desde el soneto inicial, manteniéndose la misma en cada uno de los cinco de que consta. Imaginar a Miguel como Antonio y a Antonio como Miguel suponía el cruce de sus biografías, y por eso Miguel, que es castellano de nacimiento, se muestra añorante de una infancia sevillana que no fue la suya, sino la de Machado, que vino al mundo y creció en Sevilla hasta que, a los ocho años, se trasladaría a Madrid con su familia. El tirón de Sevilla, así como su luz, sus aires y sus aromas son recreados en los sucesivos textos, todos concebidos a modo de confesión de amor al espacio geográfico nativo, que se evoca desde unas tierras castellanas que nunca pudieron hacer olvidar las orillas béticas del Guadalquivir, como se concluye en las dos estrofas finales del quinto de los sonetos, en los que le asegura a su patria chica:

\footnotetext{
No te abandonaré. Y aunque tu ardiente

cielo se quede atrás, graciosamente,

temiendo al cierzo arisco de Castilla,

serás siempre el secreto de mi infancia:

primer sangre de amor por mi mejilla...,

¡beso herido de ausencia y de distancia ${ }^{32 !}$
}

\footnotetext{
${ }^{31}$ Bajo su título aducía Alcaide una cita machadiana: los dos versos iniciales del poema "Retrato", de Campos de Castilla: "Mi infancia son recuerdos de un patio de Sevilla, / y un huerto claro donde madura el limonero;". Cf. Machado (2007, 144).

32 Íntimo trébol, 76.
} 


\section{BIBLIOGRAFÍA}

Alcaide Sánchez, J. (2001): Íntimo trébol, Julián Créis Córdoba y Matías Barchino (eds.), Valdepeñas, Asociación de Amigos de Juan Alcaide.

Echeverría, J. (1985): “Los nombres de Antonio Machado”, Anthropos, 50: 118-119.

González Moreno, P. A. (1988): “Juan Alcaide: el paisaje interior”, en su libro Aproximación a la poesía manchega, Ciudad Real, Diputación.

González Moreno, P. A. (2004): “La gracia de la espiga: Penúltima reivindicación de Juan Alcaide", Álbum poético 2003. Homenaje a Francisco Créis, Valdepeñas, Asociación Amigos de Juan Alcaide.

Llamazares González, R. (2003): Vida y obra de Juan Alcaide Sánchez, Valdepeñas, Ayuntamiento.

Machado, A. Poesías completas (2007): Madrid: Espasa Calpe. 